\title{
MAPEAMENTO DOS ATIVOS TECNOLÓGICOS DO IF SUDESTE MG COMO INSTRUMENTO NORTEADOR PARA A POLÍTICA INSTITUCIONAL DE INOVAÇÃO
}

\author{
Flávia Couto Ruback Rodrigues*; João Otávio de Barros Berbert; Maria Luiza Firmiano \\ Teixeira $^{3}$, Rafael Lourenço Luz
}

\begin{abstract}
Instituto Federal do Sudeste de Minas Gerais - Campus Juiz de Fora. Rua Bernardo Mascarenhas, 1283 - Bairro Fábrica 36080-001 - Juiz de Fora - MG (*flavia.ruback@ifsudestemg.edu.br)
\end{abstract}

\begin{abstract}
RESUMO
No Brasil, muito tem se discutido sobre a relação Universidade-Empresa. À medida que a inovação tecnológica impulsiona o desenvolvimento econômico, as empresas necessitam de conhecimentos e tecnologias gerados em ambientes acadêmicos. Se por um lado o setor produtivo muitas vezes desconhece a possibilidade de firmar parcerias tecnológicas com universidades, a ausência de estruturas organizacionais próprias para a gestão da inovação nesses ambientes tem se tornado uma barreira para o desenvolvimento de parcerias entre esses dois atores. Nesse sentido, torna-se cogente que a academia detenha um autoconhecimento de seu potencial técnico, para assim, poder configurar o setor produtivo como receptor do conhecimento gerado por meio de pesquisas. Destarte, neste artigo será exposto o Mapeamento dos Ativos Tecnológicos do IF Sudeste MG como um instrumento primordial capaz de subsidiar o processo de tomada de decisão em ciência, tecnologia e inovação visando à construção de um ambiente propício para a interação UniversidadeEmpresa.
\end{abstract}

Palavras- Chave: Inovação; Prospecção Tecnológica; Interação Universidade-Empresa.

\begin{abstract}
In Brazil, it has been largely discussed the relation between Universities and Enterprises. As technological innovations promote the economic development, the enterprises require knowledge and technologies created in academic environments. Given that the productive sector often ignores the chances to sign technological partnerships with universities, the lack of own organizational structures to manage innovation on these environments consists on a barrier to the development of business relations between these two sides. This way it is cogent that the academy possess a self knowledge of its technical potential, therefore the productive sector can be configured as the receptor of knowledge that is generated by research. Thus, this paper will show the Technological Asset Mapping of IF Sudeste MG as a prime instrument capable of finance the decision making process on science, technology and innovation, aiming to build a friendly environment for the purpose of university-industry interactions.
\end{abstract}

Keywords: Innovation; Technological Prospection; University-Industry Interaction.

Área tecnológica: Prospecções Institucionais

Cadernos de Prospecção - ISSN 1983-1358. Salvador, BA/BR - 2013. vol.6, n.3, p.379-385.

D.O.I.: 10.9771/S.CPROSP.2013.006.0042 


\section{INTRODUÇÃO}

Na dinâmica de desenvolvimento da economia globalizada, o fator inovação torna-se fundamental para aumentar a competitividade do setor empresarial brasileiro. Assim sendo, a interação entre instituições de ensino, governo e empresas torna-se cogente na transformação do conhecimento em inovação tecnológica. Conforme modelo Hélice Tríplice, o ator principal são as instituições de ensino, por serem as detentoras do conhecimento. Além de ensino e pesquisa, tais instituições incorporam uma terceira missão, a de interveniente ativo no processo de desenvolvimento econômico através da criação de conhecimento científico e tecnológico aplicado e, consequentemente, inovação (ETZKOWITZ, LEYDESDORFF, 2000).

Recentemente, as Universidades estão sendo solicitadas a expandir o seu papel, interagindo mais com outros setores de forma a ampliar seu retorno para a sociedade, basta observar o conteúdo da chamada Lei de Inovação, cujo teor visa implantar condições favoráveis para essa relação.

Portanto, torna-se primordial o autoconhecimento da infraestrutura tecnológica institucional como instrumento norteador para as futuras ações de prospecção tecnológica, que, nas palavras de (COELHO, 2003), é o processo que se ocupa de procurar, sistematicamente, examinar o futuro de longo prazo da ciência, da tecnologia, da economia e da sociedade, com o objetivo de identificar áreas de pesquisa estratégica e as tecnologias genéricas emergentes que tem a propensão de gerar os maiores benefícios econômicos e sociais.

Dessa forma, por meio desse trabalho, será exposto o Mapeamento dos Ativos Tecnológicos do IF Sudeste MG como um instrumento capaz de subsidiar o processo de tomada de decisão em ciência, tecnologia e inovação visando à construção de um ambiente propício para a interação UniversidadeEmpresa.

\section{REVISÃO DE LITERATURA}

Com a promulgação da Lei 11.892 de 29 de dezembro de 2008, que cria os Institutos Federais de Educação, Ciência e Tecnologia (IFs), inicia-se a história do Instituto Federal do Sudeste de Minas Gerais (IF Sudeste MG). A Instituição multicampi é composta pelo Campus Barbacena (antiga Escola Agrotécnica Federal de Barbacena), Campus Juiz de Fora (antigo Colégio Técnico Universitário), Campus Rio Pomba (antigo CEFET Rio Pomba), Campus Muriaé, Campus São João Del Rei e Campus Santos Dumont.

Alguns dos objetivos dos IFs elencados pela lei são: realizar pesquisas aplicadas, estimulando o desenvolvimento de soluções técnicas e tecnológicas, estendendo seus benefícios à comunidade e; desenvolver atividades de extensão de acordo com os princípios e finalidades da educação profissional e tecnológica, em articulação com o mundo do trabalho e os segmentos sociais, e com ênfase na produção, desenvolvimento e difusão de conhecimentos científicos e tecnológicos (BRASIL, 2008). Os objetivos citados vão ao encontro das diretrizes governamentais expostas na Lei de Inovação, que estabelece que toda Instituição de Ciência e Tecnologia (ICT) deve dispor de Núcleo de Inovação Tecnológica (NIT), próprio ou em associação com outra ICT, com a finalidade de gerir sua política de inovação (BRASIL, 2004).

Nesse contexto, o Núcleo de Inovação e Transferência de Tecnologia do IF Sudeste MG (NITTEC) tem como objetivos gerir a política de inovação do IF Sudeste MG, proteger as invenções desenvolvidas no âmbito da instituição e transferi-las para o setor produtivo, permitindo a integração com a comunidade e a contribuição para o desenvolvimento tecnológico e social da 
região. O Núcleo é subordinado à Pró-Reitoria de Pesquisa e Inovação do IF Sudeste MG, e é composto pela Diretoria do NITTEC, Conselho do NITTEC, Coordenador Geral de Inovação Tecnológica e Secretário Executivo, seções de Projetos de Inovação, de Propriedade Intelectual e a seção de Articulação e Prospecção de Oportunidades de Inovação. Adicionalmente, conta com representatividade em todos os seis campus, por meio dos Gerentes de Inovação Tecnológica e Gerentes de Prospecção de Oportunidades de Inovação.

Mayerhoff (2008) define Estudos de Prospecção como uma ferramenta básica para a fundamentação nos processos de tomada de decisão em diversos níveis na sociedade moderna. A mesma autora define a Prospecção Tecnológica como:

\begin{abstract}
um meio sistemático de mapear desenvolvimentos científicos e tecnológicos futuros capazes de influenciar de forma significativa uma indústria, a economia ou a sociedade como um todo Os métodos de prospecção vêm sendo usados, há várias décadas, por organizações públicas e privadas de diversos países, como uma ferramenta para orientar os esforços empreendidos para o desenvolvimento de tecnologias. A utilização mais sistemática desses métodos se deu a partir da década de 50, tendo se intensificado a partir da década de 80. É interessante observar a coincidência entre a intensificação da utilização desses métodos e o acelerado desenvolvimento tecnológico da atualidade.
\end{abstract}

Dessa forma, no âmbito de sistemas de Ciência, Tecnologia e Inovação (C,T\&I), os exercícios de prospecção tecnológica têm sido considerados fundamentais para promover a criação da capacidade de organizar sistemas de inovação que respondam aos interesses da sociedade.

Nesse sentido, no próximo item serão abordados alguns resultados quantitativos do mapeamento dos ativos tecnológicos do IF Sudeste MG.

\title{
RESULTADOS E DISCUSSÃO
}

No ano de 2011 foi dado início o trabalho de planejamento do Mapeamento de Ativos Tecnológicos do IF Sudeste MG, sob responsabilidade do NITTEC e coordenado pela seção de Articulação e Prospecção de Oportunidades de Inovação. Ele consiste na coleta de dados quantitativos e qualitativos acerca do ambiente e das ações que envolvem questões relacionadas à inovação, propriedade intelectual e transferência de tecnologia.

$\mathrm{O}$ estudo foi realizado via entrevista pessoal junto aos docentes e técnicos administrativos em educação (neste caso, apenas aqueles que também atuassem como pesquisadores), em cada um dos Campus pelos respectivos Gerentes de Inovação ${ }^{1}$ e sua equipe. Como instrumento padrão, utilizouse um questionário virtual, contendo questões tais como: (1) área de atuação; (2) linhas de pesquisa; (3) número e descrição dos projetos de pesquisa; (4) tipo de financiamento envolvido; (5) cooperação de pesquisadores de outras instituições ou alunos bolsistas, (6) envolvimento de empresas privadas; (7) número e modalidades de registros de propriedade intelectual; (8), interesse na criação de empresas de base tecnológica e na prestação de serviços tecnológicos, entre outras.

De acordo com informações fornecidas pela Coordenação de Articulação e Prospecção de Oportunidades de Inovação do NITTEC, o levantamento de dados obteve cerca de $88 \%$ de participação, resultado suficientemente expressivo para a sua consideração enquanto instrumento de

\footnotetext{
${ }^{1}$ Conforme o Regimento Interno do Núcleo de Inovação e Transferência de Tecnologia
} 
decisão para o direcionamento das políticas de pesquisa e inovação do IF Sudeste MG (CÓSER, 2012).

Cumpre ressaltar que, para fins deste artigo, serão apresentadas apenas as informações consideradas mais relevantes para subsidiar as considerações ao final do trabalho.

Conforme se observa nos resultados, as áreas das pesquisas do IF Sudeste MG encontram-se em variadas áreas do conhecimento destacando-se as ciências exatas e da terra, bem como as ciências agrárias e as engenharias, conforme Figura 1 a seguir:

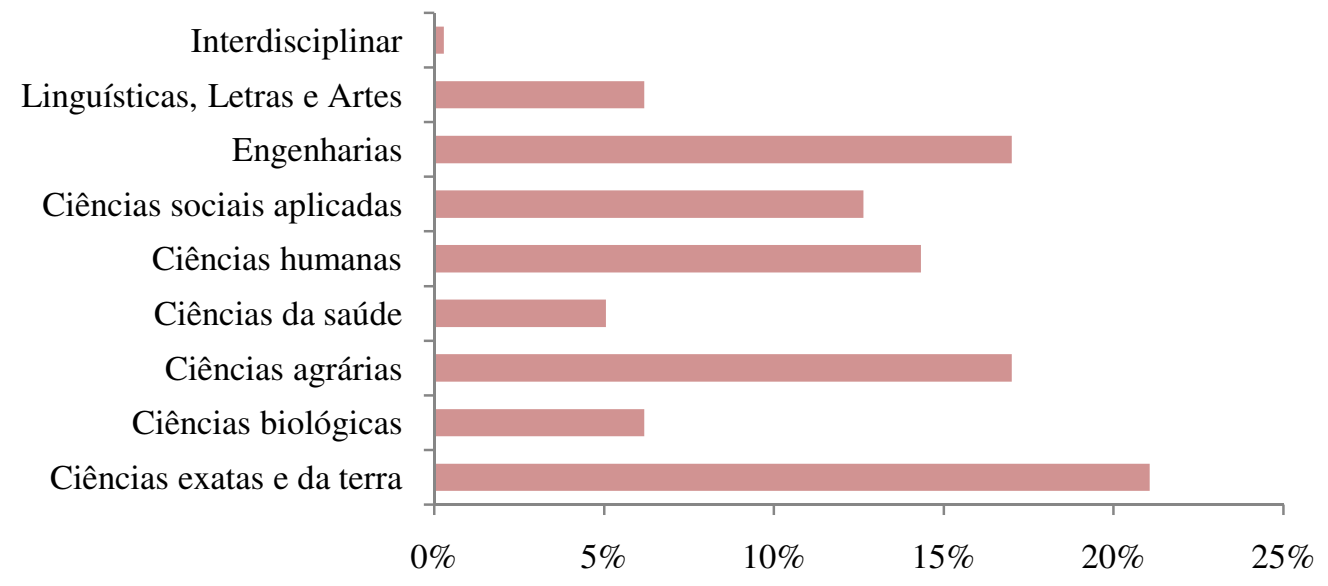

Figura 1: Distribuição das pesquisas por área do conhecimento. Fonte: Autoria própria, 2012.

Em termos de projetos de pesquisa, embora a Instituição seja nascente, uma análise quantitativa dos resultados mostra que os mesmos são bastante expressivos, destacando a atuação dos campus Juiz de Fora, contando com 147 projetos, e Rio Pomba, contando com 240 projetos, conforme demonstra a Figura 2. Cumpre ressaltar que os projetos realizados anteriormente ao ingresso do servidor na instituição não foram contemplados na presente pesquisa.

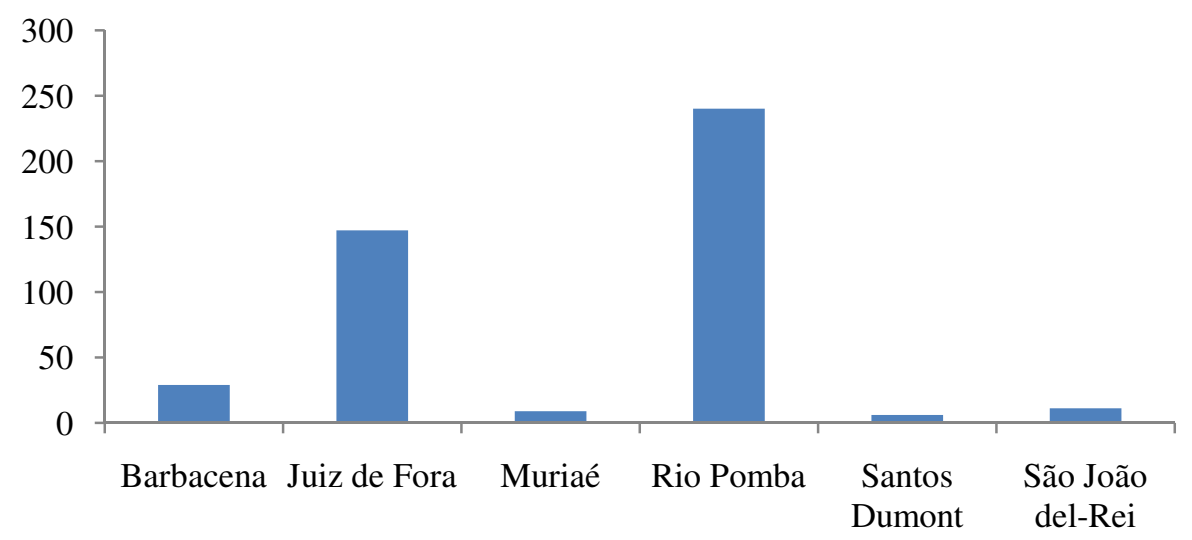

Figura 2: Distribuição do número de projetos por campus. Fonte: Autoria própria, 2012. 
Quanto à prática de busca de informações tecnológicas em bases de patentes, destaca-se que um pequeno percentual de entrevistados possui esse hábito - apenas 16\% -, conforme consta na Figura 3.

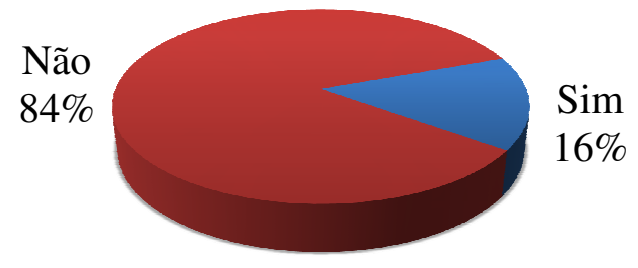

Figura 3: Relação de entrevistados que tem a prática de busca em bases de patente.Fonte: elaborado pelos autores

Esse dado aponta para uma necessidade de capacitação dos entrevistados no sentido de qualificá-los em busca em bases de patentes para que possam usar tal ferramenta como referencial bibliográfico para as pesquisas a serem desenvolvidas, como também evitar um dispêndio de recursos desnecessários com pesquisas que já possuem seus resultados protegidos legalmente.

A intenção de criação de empresa de base tecnológica, considerando as possibilidades legais de atuação de docentes em regime de dedicação exclusiva, foi apontada por $21 \%$ dos entrevistados, conforme Figura 4.

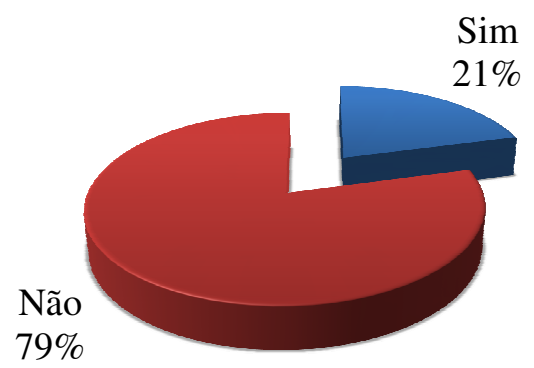

Figura 4: Relação de entrevistados que têm interesse em criar empresa de base tecnológica. Fonte: Autoria própria, 2012.

Esse número reflete a preponderância das principais áreas de atuação da instituição (Ciências exatas e da terra e Engenharias), propensas à geração de novas tecnologias.

Outrossim, a grande maioria dos entrevistados possui interesse em realizar pesquisas em cooperação com empresas.

Essa informação evidencia a necessidade de difusão das possibilidades legais de interação universidade-empresa, sendo imperiosa a diluição do mito da impossibilidade de um servidor 
público, em regime de dedicação exclusiva, realizar outra atividade, além das comumente praticadas institucionalmente.

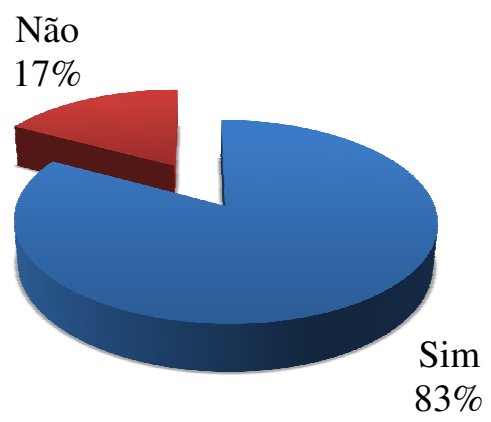

Figura 5: Relação de entrevistados que têm interesse em prestar serviços externos remunerados. Fonte: Autoria própria, 2012.

\section{CONSIDERAÇÕES FINAIS}

Tendo em vista os dados coletados, é possível traçar uma política de desenvolvimento das áreas de pesquisa, inovação e propriedade intelectual no âmbito do IF Sudeste MG.

Levando em conta os resultados do mapeamento, principalmente nos campus em que há maior presença de projetos de pesquisa (Rio Pomba e Juiz de Fora), percebe-se que o principal mecanismo de interação entre a instituição e empresas a ser estimulado no momento é a prestação de serviços tecnológicos e a transferência de tecnologia.

O empreendedorismo acadêmico ainda se apresenta bastante incipiente na instituição, dessa forma mecanismos de estímulo à geração de spin-offs e a implantação de pré-incubadoras ou incubadoras devem ser pensados com bastante cautela, já que a opção de empreender um negócio de base tecnológica, em geral, não é desejada pelo público entrevistado. Já nos demais campus, detectou-se um estágio elementar da pesquisa científica e tecnológica, sendo mister, portanto, intensificar o incentivo à pesquisa científica e tecnológica nesses ambientes.

Foi possível constatar alguns potenciais institucionais, tais como a área de laticínios, que já detém o potencial necessário para interação com o mercado externo, assim como áreas que ainda demandam investimento e incentivo, como as áreas de ciências biológicas.

É importante salientar que este trabalho não pretende esgotar o tema, mas apontar algumas ações, de maneira preliminar, a serem fomentadas na instituição para que se desenvolva um ambiente propício para o desenvolvimento de pesquisas com potencial de interação com a sociedade. 


\section{REFERÊNCIAS}

BRASIL. Lei no 10973, de 2 de dezembro de 2004. Dispõe sobre incentivos à inovação e à pesquisa científica e tecnológica no ambiente produtivo e dá outras providências. Disponível em: <http://www.planalto.gov.br/ccivil_03/_ato2004-2006/2004/Lei/L10.973.htm>. Acessado em: 01 mar. 2012.

BRASIL. Lei $\mathrm{n}^{\mathrm{o}}$ 11892, de 29 de dezembro de 2008. Institui a Rede Federal de Educação Profissional, Científica e Tecnológica, cria os Institutos Federais de Educação, Ciência e Tecnologia, e dá outras providências.

COELHO, G. M. Prospecção tecnológica: metodologias e experiências nacionais e internacionais. Rio de Janeiro: INT, 2003.

CÓSER, I. Relatórios. [mensagem pessoal]. Mensagem recebida por <flavia.ruback@ifsudestemg.edu.br> em 16 out. 2012.

ETZKOWITZ, H.; LEYDESDORFF, L. The dynamics of innovation: from national systems and model 2 to a triple helix of university-industry-government relations. Research Policy. v. 29, p. 109-123, 2000.

MAYERHOFF, Z. D. V. L. Uma Análise Sobre os Estudos de Prospecção Tecnológica. Cadernos de prospecção, n. 1, 2008. 